\title{
EFFECTIVENESS OF POLYETHYLENE SKIN WRAP IN PREVENTION OF HYPOTHERMIA IN PRETERM AND LOW BIRTH WEIGHT NEONATES
}

\author{
Goher Ali Khan, Usman Riaz*, Tariq Aziz**, Sara Iqbal***, Tariq Aziz Qureshi****, Major Hina Kanwal Shafaat***** \\ Combined Military Hospital Mangla/National University of Medical Sciences (NUMS) Pakistan, *Combined Military Hospital Pano Aqil/National University of \\ Medical Sciences (NUMS) Pakistan, ${ }^{* *}$ Combined Military Hospital Abbottabad/National University of Medical Sciences (NUMS) Pakistan, ${ }^{* * * P a k ~ E m i r a t e s ~}$ \\ Military Hospital/National University of Medical Sciences (NUMS) Rawalpindi Pakistan, ****Midland Regional Hospital, Portlaoise, Ireland, ****Armed Forces \\ Institute of Rehabilitation Medicine/National University of Medical Sciences (NUMS) Rawalpindi Pakistan
}

\section{ABSTRACT}

Objective: To establish the effectiveness of polyethylene skin wrap in prevention of neonatal hypothermia in preterm and low birth weight neonates.

Study Design: Quasi-experimental study.

Place and Duration of Study: Department of Pediatrics, Combined Military Hospital Quetta, from May 2015 to Apr 2017.

Methodology: A total of 176 neonates were enrolled according to the inclusion and exclusion criteria, through non-probability consecutive sampling. Eighty eight newborns were randomly distributed to each of group " $A$ " and " $B$ " by lottery method. The intervention group " $\mathrm{A}$ " infants were wrapped in a polyethylene skin wrap from shoulders down while the control group " $\mathrm{B}$ " newborns were wrapped with conventional blankets. After shifting to neonatal intensive care unit, axillary temperatures were recorded with similar pediatric digital thermometers upon admission and after one hour and two hours following admission in the two groups.

Results: The mean temperatures measured at one hour and two hours after admission showed significant statistical improvements in the intervention group as compared to the control group $(<0.05)$.

Conclusion: The use of polyethylene skin wrap in preterm and low birth weight neonates potentially offers a useful intervenetion in prevention of neonatal hypothermia.

Keywords: Hypothermia, Low birth weight, Preterm, Polyethylene skin wrap.

This is an Open Access article distributed under the terms of the Creative Commons Attribution License (https://creativecommons.org/licenses/by-nc/4.0/), which permits unrestricted use, distribution, and reproduction in any medium, provided the original work is properly cited.

\section{INTRODUCTION}

Birth, especially in preterm and low birth weight (LBW) neonates, is associated with many physiologic challenges to the neonatal body. One of the challenges is to maintain body temperature. Neonatal hypothermia is a well-known factor associated with significant morbidity and mortality ${ }^{1}$. Up to half of all preterm neonates experience some degree of hypothermia. The degree of hypothermia is directly proportional to the degree of prematurity ${ }^{2}$. A multitude of physiological risk factors contribute to the hypothermia like inappropriate vasomotor control, deficient subcutaneous fat, increased body surface area to body weight ratio, mal adjustment from the fetal to neonatal blood circulation, and a keratin deficient immature superficial skin layer 3 . There are also a number of pathological risk factors including neonatal infections/sepsis, coagulopathies, neonatal acidosis, and respiratory distress syndrome (RDS). The heat loss from the neonatal body is governed by the four classic mechanisms namely radiation, conduction, convection, and evaporation ${ }^{4}$. The last one takes special importance in neonates with LBW and

Correspondence: Dr Tariq Aziz, Classified Specialist, Combined Military Hospital Abbottabad Pakistan

Received: 29 Nov 2019; revised received: 22 Jan 2020; accepted: 24 Jan 2020 the effects of evaporation are more so if the neonate is preterm as well. For neonates the normal range of body temperatures is considered to be between 36.5$37.7^{\circ} \mathrm{C}$. Temperatures between $32-36^{\circ} \mathrm{C}$ are consistent with moderate degree of hypothermia and temperature $<32^{\circ} \mathrm{C}$ is considered severe hypothermia ${ }^{5}$. The physiologic complications that occur as a result of neonatal hypothermia comprise increased oxygen consumption, metabolic acidosis, hypoglycemia, lowered cardiac output and increased peripheral vascular resistance $^{6}$. These all then contribute to deterioration of neonatal condition especially in newborns with LBW. A newborn's body reacts differently to hypothermia compared to that of an adult 7 . Particularly notable phenomenon is the lack of shivering. A neonate's body responds to hypothermia by increasing sympathetic activity that results to an increase in noradrenaline and thyroid stimulating hormone that resultantly increases levels of thyroid hormones T3 and T48. Thyroid hormones boost body's heat production through enhanced fat oxidation. Prevention of hypothermia in hospital setup starts with simple measures including maintaining a higher delivery room temperature, skin to skin contact between mother and newborns, and placing a cap on the newborn's head ${ }^{9}$. Some of the more sophisticated methods to prevent hypothermia include use of 
incubators, radiant warmers, and warming mattresses. Perhaps a single method that has shown effectiveness for prevention of neonatal hypothermia is polyethylene occlusive skin wrapping of the wet newborn ${ }^{10}$. In this rather simple method, which is being adopted widely, the newborn is not dried and is immediately wrapped from shoulders down with a clear polyethylene skin wrap. Polyethylene skin wraps work by reducing the evaporative and convective heat losses, and the insensible water losses. They also reduce the rate of metabolic heat production.

Although this simple intervention for neonatal hypothermia is increasingly being employed all over the world including our part of the world, but to our knowledge studies determining its efficacy are limited in Pakistan. Our current study aims to determine the effectiveness of polyethylene skin wraps in prevention of neonatal hypothermia in preterm and LBW newborns.

\section{METHODOLOGY}

This quasi-experimental study was carried out at NICU of a tertiary care teaching Hospital namely Combined Military Hospital Quetta, from May 2015 to April 2017. After acquiring authorization from the hospital ethics committee, 176 newborns of either gender who fulfilled the inclusion criteria of having gestational age between 28-36 weeks, and birth weight between $1-2.5 \mathrm{~kg}$, were enrolled, through non-probability consecutive sampling, who's parents had consented to take part in the study. Gestational age was determined using last menstrual period, fundal height, and ultrasonography by qualified obstetrician/radiologist. Excluded from the study were the infants born with major open congenital anomalies like myelomeningocele, gastroschisis, and congenital dermatological diseases. The sample size was calculated using sample size calculator of world health organisation keeping level of significance at five percent and power of the test at eighty percent ${ }^{5}$.

After explaining the aims and advantages of the research study, informed permission was acquired from parents of every neonate. Eighty eight newborns were randomly distributed each to group " $A$ " and " $B$ " by lottery method. The intervention group " $\mathrm{A}$ " infants were wrapped in a polyethylene skin wrap from shoulders down wrapping the trunk and all four limbs. The control group "B" newborns were similarly wrapped with blankets provided by the family. Newborns in both the groups received same standard care including a short-lived period of drying on their mother's abdo- men while their umbilical cord was being dealt with and the placenta was being delivered. Next, all the neonates were transferred from the labour / operating room to the NICU and were put under a warmer after recording their vital signs making sure that the newborns were medically stable. Next, axillary temperatures were recorded with similar pediatric digital thermometers upon admission and after one hour and two hours of admission in both the groups. Data were collected using especially deliberated forms and were then analysed using the statistical analysis program namely Statistical Package for the Social Sciences (SPSS version 17). Frequency and percentages were used for measuring qualitative variables like gender while for quantitative variables like temperature, mean and standard deviations (SD) were calculated. Independent student's t-test was used to compare the results between the two groups, and $p$-values $\leq 0.05$ were taken as statistically significant.

\section{RESULTS}

All 176 patients finished the study with none withdrawn. Basic features of the participants are depicted in table-I. Out of total 176 neonates distributed in to the two groups, most were males $(52.27 \%$ in group A and $51.13 \%$ in group B). Mean gestational age was $25.5 \pm 1.6$ weeks in group A while it was $25.6 \pm 1.6$ weeks in group B. Mean birth weight of the infants was $0.765 \pm 0.231$ kilograms in the intervention group while it was $0.787 \pm 0.254$ kilograms in the control group. The mode of delivery was mostly Caesarian (92.04\% for group A and $89.77 \%$ for group B). While mean temperatures at admission as measured in degree Celsius were comparable in the two groups, the mean temperatures measured at one hour and two hours after admission showed significant statistical improvements in the intervention group " $\mathrm{A}$ " as compared to the control group " $\mathrm{B}$ " $(<0.05)$ (table-II).

\section{DISCUSSION}

Maintaining adequate body temperature is one of the well recognized foremost and fundamental necessities for the health of all neonates ${ }^{11,12}$. Neonatal hypothermia continues to haunt neonatal healthcare professionals even at the very best of the centers. It is defined as a core body temperature lower than the normal range of $36.5-37.7^{\circ} \mathrm{C}^{5}$. Various associated risk factors for neonatal hypothermia include prematurity, LBW, intra-uterine growth restriction, central nervous system diseases, and some congenital anomalies like gastroschisis and exomplalos ${ }^{13}$. Of these the first two are often the substantially contributing factors. Immedia- 
tely following delivery, heat loss gradually sets in at a rate of $0.1^{\circ} \mathrm{C}$ per minute for term neonates, and at even faster rates for preterm and LBW neonates ${ }^{14}$. A neonate's body responds to hypothermia in a different way compared to that of an adult ${ }^{7}$. Predominantly noteworthy phenomenon is the lack of shivering. A neonates without any associated adverse reactions save for possible hindrance in the process of resuscitation, should need arises ${ }^{17,19}$.

The results of our study showed an insignificant variation in temperature of neonates at admission

Table-I: Basic demographics.

\begin{tabular}{|c|c|c|c|c|c|}
\hline \multirow[t]{2}{*}{ Characteristic } & \multicolumn{2}{|c|}{$\begin{array}{c}\text { Group "A" } \\
\text { (Intervention group) }(\mathrm{n}=88)\end{array}$} & \multicolumn{2}{|c|}{$\begin{array}{c}\text { Group "B" } \\
\text { (Control group) }(n=88)\end{array}$} & \multirow[t]{2}{*}{$p$-value* } \\
\hline & n $(\%)$ & Mean \pm SD & n (\%) & Mean \pm SD & \\
\hline Gestational age (weeks) & - & $25.5 \pm 1.6$ & - & $25.6 \pm 1.6$ & 0.65 \\
\hline Gender (Female/Male) & $42(47.72) / 46(52.27)$ & - & $43(48.86) / 45(51.13)$ & - & 0.73 \\
\hline Birth weight (Kgs) & - & $0.765 \pm 0.231$ & - & $0.787 \pm 0.254$ & 0.75 \\
\hline Delivery mode (Vaginal/Caesarian) & $7(7.95) / 81(92.04)$ & - & $9(10.22) / 79(89.77)$ & - & 0.63 \\
\hline
\end{tabular}

Table-II: Outcome results of the patients.

\begin{tabular}{|c|c|c|c|}
\hline \multirow[t]{2}{*}{ Outcome Variable } & $\begin{array}{c}\text { Group "A" } \\
\text { (Intervention group) }(n=88)\end{array}$ & $\begin{array}{c}\text { Group “B” } \\
\text { (Control group) }(n=88)\end{array}$ & \multirow[t]{2}{*}{$p$-value* } \\
\hline & Mean \pm SD & Mean \pm SD & \\
\hline Temperature at admission $\left({ }^{\circ} \mathrm{C}\right)$ & $36.1 \pm 0.7$ & $35.2 \pm 0.6$ & 0.25 \\
\hline Temperature at 1 hour after admission $\left({ }^{\circ} \mathrm{C}\right)$ & $36.6 \pm 0.5$ & $36.3 \pm 0.5$ & 0.01 \\
\hline Temperature at 2 hours after admission $\left({ }^{\circ} \mathrm{C}\right)$ & $36.9 \pm 0.6$ & $36.3 \pm 0.7$ & 0.02 \\
\hline
\end{tabular}

newborn's body reacts to hypothermia by increasing sympathetic activity that results in an increase in noradrenaline and thyroid stimulating hormone that subsequently increases serum levels of thyroid hormones T3 and T48. Thyroid hormones enhance body's heat production through increased fat oxidation. Prevention of neonatal hypothermia in hospital setup begins with the simplest of measures including maintaining a higher delivery/operating room temperature, encouraging skin to skin contact between mother and newborns, and placing a cap on the newborn's head ${ }^{9}$. Some of the more advanced options available to prevent hypothermia include use of incubators, radiant warmers, and warming mattresses. Perhaps a single method that has shown effectiveness for prevention of neonatal hypothermia is the use of polyethylene occlusive skin wrapping of the wet newborn ${ }^{10}$. Impending hypothermia warrants prompt use of heat loss prevention strategies to prevent potential complications. Such strategies generally act either by providing heat from external heat sources or by interventions to prevent indigenous heat loss by barrier methods ${ }^{15}$. One such barrier intervention is the use of polyethylene skin wraps which work by reducing the evaporative and convective heat losses, and the insensible water losses. Such occlusive skin wrappings also reduce the rate of metabolic heat production ${ }^{16}$. Polyethylene skin wraps have proven to be simple and effective in reducing the risk of neonatal hypothermia in both term and preterm between the two groups $(p=0.25)$, while there was a significant variation in temperature of neonates at one hour and two hours after admission between the two groups $(p=0.01 \& 0.02)$. Mean temperature of neonates reached to nearly $37^{\circ} \mathrm{C}$ in the intervention group at two hours after admission. The results of our current study are in general agreement with a number of other international research studies. A meta-analysis concluded that plastic skin wrapping was linked to a reduction in hypothermia both in preterm and term infants ${ }^{13}$. A randomized controlled trial from India also showed that polyethylene skin wrapping offered rapid and persistent temperature control and was effective at preventing neonatal hypothermia in preterm infants ${ }^{15}$. Another meta-analysis from China considered plastic wraps to be effective and safe additional intervention for prevention of hypothermia in preterm neonates ${ }^{16}$. Another multicenter randomized controlled trial concluded that total body wrapping was effective at preventing neonatal hypothermia in very preterm newborns ${ }^{18}$. Yet another clinical trial from Iran similarly concluded that the combined usage of a plastic bag and a plastic hat was more efficacious at preventing neonatal hypothermia as compared to the use of a plastic bag and a cotton hat cmbined ${ }^{20,21}$.

\section{RECOMMENDATION}

Polyethylene skin wraps should be used to prevent hypothermia and its associated complications 
to minimize the length of hospital stays and reduce the associated costs.

\section{CONCLUSION}

To sum up, our results suggest that the use of polyethylene skin wrap is effective in prevention of hypothermia and its associated complications in preterm and LBW infants.

\section{CONFLICTS OF INTEREST}

This study has no conflict of interest to be declared by any authors.

\section{REFERENCES}

1. Mank A, van Zanten HA, Meyer MP, Pauws S, Lopriore E, te Pas AB. Hypothermia in preterm infants in the first hours after birth: Occurrence, course and risk factors. PloS one 2016; 11(11): e0164817.

2. Wilson E, Maier RF, Norman M, Misselwitz B, Howell EA, Zeitlin J, et al. Admission hypothermia in very preterm infants and neonatal mortality and morbidity. J Pediatr 2016; 175: 61-67.

3. Azad K, Mathews J. Preventing newborn deaths due to prematurity. Best Pract Res Clin Obstet Gynaecol 2016; 36: 131-44.

4. Caldas JP, Millen FD, Camargo JF, Castro PA, Camilo AL, Marba ST. Effectiveness of a measure program to prevent admission hypothermia in very low-birth weight preterm infants. J Pediatr 2018; 94(4): 368-73.

5. Yip WY, Quek BH, Fong MC, Ong SS, Lim BL, Lo BC, et al. A quality improvement project to reduce hypothermia in preterm infants on admission to the neonatal intensive care unit. Int J Qual Health Care 2017; 29(7): 922-28.

6. Laptook AR, Bell EF, Shankaran S, Boghossian NS, Wyckoff MH, Kandefer $S$, et al. Admission temperature and associated mortality and morbidity among moderately and extremely preterm infants. J Pediatr 2018; 192(1): 53-59.

7. McCall EM, Alderdice F, Halliday HL, Vohra S, Johnston L. Interventions to prevent hypothermia at birth in preterm and/or low birth weight infants. Cochrane Database Syst Rev 2018; 2: CD004210.

8. Frazer M, Ciarlo A, Herr J, Briere CE. Quality improvement initiative to prevent admission hypothermia in very-low-birth-weight newborns. J Obstet Gynecol Neonat Nurs 2018; 47(4): 520-28.

9. Ting JY, Synnes AR, Lee SK, Shah PS. Association of admission temperature and death or adverse neurodevelopmental outco- mes in extremely low-gestational age neonates. J Perinatol 2018; 38(7): 844

10. Tay VY, Bolisetty S, Bajuk B, Lui K, Smyth J. The new south wales and the australian capital territory neonatal intensive care units' data collection. Admission temperature and hospital outcomes in extremely preterm infants. J Paediatr Child Health 2019; 55(2): 216-23.

11. Harer MW, Vergales B, Cady T, Early A, Chisholm C, Swanson $\mathrm{JR}$. Implementation of a multidisciplinary guideline improves preterm infant admission temperatures. J Perinatol 2017; 37(11): 1242-47.

12. Fawcett K. Preventing admission hypothermia in very low birth weight neonates. Neonatal Network 2014; 33(3): 143-49.

13. Oatley HK, Blencowe H, Lawn JE. The effect of coverings, including plastic bags and wraps, on mortality and morbidity in preterm and full-term neonates. J Perinatol 2016; 36(S1): S83.

14. Nimbalkar SM, Patel VK, Patel DV, Nimbalkar AS, Sethi A Phatak A. Effect of early skin-to-skin contact following normal delivery on incidence of hypothermia in neonates more than 1800g: randomized control trial. J Perinatol 2014; 34(5): 364-68.

15. Nimbalkar SM, Khanna AK, Patel DV, Nimbalkar AS, Phatak AG. Efficacy of polyethylene skin wrapping in preventing hypothermia in preterm neonates $(<34$ Weeks): A parallel group nonblinded randomized control trial. J Trop Pediatr 2018; 2018: 1-5.

16. Li S, Guo P, Zou Q, He F, Xu F, Tan L. Efficacy and safety of plastic wrap for prevention of hypothermia after birth and during NICU in preterm infants: a systematic review and meta-analysis. PloS one 2016; 11(6): e0156960.

17. Çaglar S, Gözen D, İnce Z. Heat loss prevention (help) after birth in preterm infants using vinyl isolation bag or polyethylene wrap. J Obstetr Gynecol Neonat Nurs 2014; 43(2): 216-23.

18. Doglioni N, Cavallin F, Mardegan V, Palatron S, Filippone M, Vecchiato L, et al. Total body polyethylene wraps for preventing hypothermia in preterm infants: a randomized trial. J Pediatr 2014; 165(2): 261-66.

19. Shafie H, Syed Zakaria SZ, Adli A, Shareena I, Rohana J. Polyethylene versus cotton cap as an adjunct to body wrap in preterm infants. Pediatr Intl 2017; 59(7): 776-80.

20. Talakoub S, Shahbazifard Z, Armanian AM, Ghazavi Z. Effect of two polyethylene covers in prevention of hypothermia among premature neonates. Iran J Nurs Midwifery Res 2015; 20(3): $322-26$.

21. Hsu KH, Chiang MC, Lin SW, Lin JJ, Wang YC, Lien R. Thermal blanket to improve thermoregulation in preterm infants: a randomized controlled trial. Pediatr Crit Care Med 2015; 16(7): 637-43. 